\title{
PRECARIZAÇÃO DO TRABALHO PELA TERCEIRIZAÇÃO E A NECESSIDADE DA APLICAÇÃO DA SUBORDINAÇÃO ESTRUTURAL NA ATIVIDADE-MEIO
}

Renata Canevaroli de Souza, Centro Universitário de Bauru. recanevaroli@gmail.com

\section{RESUMO}

A subordinação jurídica prevista na legislação trabalhista é pilar para a configuração da relação de emprego com consequente formação de vínculo empregatício em seus moldes padrões. No entanto, com o desenvolvimento das atividades em meio ao cenário capitalista, a relação de emprego sofreu flexibilização prejudicial, como a terceirização. Objeto do presente trabalho, a subordinação estrutural, ou seja, o comando exercido pelas tomadoras de serviços sobre o funcionário inserido em atividades-meio possui extrema importância no cenário do capital e trabalhista, dado o andamento do Projeto de Lei 4.330/2004. Este prevê regulamentação e possibilidade de terceirização, até então combatida pelo poder judiciário, amparado pela súmula 331 do Tribunal Superior do Trabalho. Assim, mediante análise bibliográfica e jurisprudencial, pode-se constatar o crescimento de atividades terceirizadas, que realizam a subordinação estrutural, ilustrada pela inserção do trabalhador na cadeia produtiva essencial da empresa, que busca mascarar obrigações e responsabilidades trabalhistas diretas, que ensejariam consequente formação de vínculo e equiparação aos empregados da tomadora de serviços.

Palavras-chave: Subordinação estrutural. Intermediação de mão-de- obra. Súmula 331 do TST. Terceirização ilícita.

\begin{abstract}
The envisaged legal subordination in labor legislation is pillar for the configuration of the employment relationship with consequent formation of formal jobs in their molds patterns. However, with the development of activities in the midst of the capitalist scenario, the relationship of employment suffered flexibilization harmful, such as the outsourcing. The object of this work, the structural subordination, i.e., the control exercised by borrowing operations of services on the employee inserted in activitiesenvironment has a great importance in the scenario of capital and labor, given the progress of the Project of Law 4.330/2004. This provides for regulation and possibility of outsourcing, until then fought by the judiciary, sustained by summing up 331 of Higher Labor Court. Thus, through bibliographic analysis and jurisprudential, can note the growth of outsourced activities, who carry out structural subordination, illustrated by the insertion of the worker in the productive chain essential of the company, that search mask direct labor obligations and responsibilities, which ensejariam consequent formation of bond and assimilation to the employees of the taker of services.
\end{abstract}

Key-words: Structural Subordination. Intermediation of labor costs. Summing up 331 of the

TST.

Illicit

outsourcing. 


\section{SEMINÁRIO DE PESQUISA EM CIÊNCIAS HUMANAS - SEPECH \\ Humanidades, Estado e desafios didático-científicos \\ Londrina, 27 a 29 de julho de 2016}

\section{INTRODUÇÃO}

Com as modificações de mercado derivadas do capital, este promoveu a flexibilização da relação de trabalho, com o intuito de reduzir os gastos, aumentar a produção e auferir mais lucro em detrimento do empregado através, neste trabalho, da terceirização.

A terceirização de serviços não possui legislação específica no ordenamento jurídico brasileiro, sendo regulamentada de modo paleativo pela Súmula 331 do Tribunal Superior do Trabalho, que reconhece esta como uma exceção à relação de trabalho, elencando permissivos e vedações para a prática desta flexibilização. Um desses permissivos, é a possibilidade de terceirizar atividade-meio, desde que ausente a subordinação.

Nesse cenário, buscou-se apresentar um breve conceito no tocante à subordinação clássica, e posteriormente, como deve ser analisada a subordinação do trabalhador terceirizado inserido na atividade-meio que seja essencial dentro cadeia produtiva de uma empresa.

Esta modalidade de subordinação é caracterizada pela atividade do trabalhador ser essencial ao produto final do tomadora de serviços, que em razão disso, exerce poder diretivo e de comando, sobre o terceirizado. Ao exercer esta subordinação, deve-se reconhecer pois, a existência de vínculo empregatício a fim de resguardar o trabalhador terceirizado, muitas vezes comercializado como força de trabalho.

Procedeu-se portanto análise bibliográfica e jurisprudencial em defesa pelo reconhecimento e aplicação da subordinação estrutural, pois, uma vez que reconhecidaa tomadora de serviços fica impedida de mascarar obrigações e responsabilidades trabalhistas diretas.

Ao final, verifica-se através do entendimento do legislador pelo projeto de lei $\mathrm{N}^{\circ} 4.330 / 2004$ o atual cenário de crise econômica e política, que busca extirpar direitos sociais. Referido projeto foi aprovação pela Câmara dos Deputados em 2015, e atualmente tramita na casa do Senado Federal.

Caso aprovado, a terceirização que deve ser exceção via de regra, poderá ser livremente realizada em confronto aos direitos trabalhistas. Será ainda permitida sucessivamente e em cadeira, como cristalina intermediação e locação de mão-de-obra, hoje, combatida.

Inegável que buscou-se no presente a demonstração da precarização das condições de trabalho praticada através da terceirização que fere a dignidade constitucionalmente protegida.

\section{DA PRECARIZAÇÃO DO TRABALHO PELA TERCEIRIZAÇÃO}

Inicialmente, a terceirização não possui conceito positivado definido em legislação própria, de modo que a presente pesquisa visou apresentar uma singela definição a partir da construção da doutrina, e jurisprudência pátria, sobre o conceito da terceirização.

Quanto a sua nomenclatura, Maurício Godinho Delgado define (2004, p. 429): “A expressão resulta de neologismo oriundo da palavra terceiro, compreendido como 


\section{SEMINÁRIO DE PESQUISA EM CIÊNCIAS HUMANAS - SEPECH \\ Humanidades, Estado e desafios didático-científicos \\ Londrina, 27 a 29 de julho de 2016}

intermediário e interveniente. Por causa disso, alguns autores associam a terceirização à colocação ou intermediação ou cessão de mão de obra".

A modalidade do trabalho terceirizado se intensivou como opção no mercado a partir dos anos 70, posteriormente à crise econômica mundial do petróleo, onde o capitalismo buscou novas formas de se reinventar a fim de gerar lucro. Desta forma, a terceirização nada mais foi que uma forma de flexibilizar o trabalho.

Essa flexibilização precariza cristalinamente o trabalhador em dois sentidos, o econômico propriamente dito, que beneficia os tomadores de serviços que visam reduzir custos de produção e responsabilidade direta sobre verbas trabalhistas, e também o político, no intuito de dividir os trabalhadores para defesa de seus direitos.

Complementa Rodrigo de Lacerda Carelli acerca da definição de terceirização (2003, p. 07):

[...] demonstra a real intenção do empresariado brasileiro no repasse a 'terceiro', no sentido de 'outro', da posição de empregador na relação empregatícia (e consequentemente da responsabilidade sobre os encargos e direitos trabalhistas) com seus empregados.

Com a adoção da terceirização e a ausência de regulamentação específica protetiva foi criada a Súmula 331 do Tribunal Superior do Trabalho, de 1993, que elencou permissivos para a terceirização como os serviços de limpeza e vigilância, as atividades-meio das empresas, vedando esta na atividade-fim, bem como a intermediação de mão-de-obra, conforme:

CONTRATO DE PRESTAÇÃO DE SERVIÇOS. LEGALIDADE (nova redação do item IV e inseridos os itens V e VI à redação) - Res. 174/2011, DEJT divulgado em 27, 30 e 31.05.2011

I - A contratação de trabalhadores por empresa interposta é ilegal, formando-se o vínculo diretamente com o tomador dos serviços, salvo no caso de trabalho temporário (Lei $\mathrm{n}^{\circ} 6.019$, de 03.01.1974).

II - A contratação irregular de trabalhador, mediante empresa interposta, não gera vínculo de emprego com os órgãos da Administração Pública direta, indireta ou fundacional (art. 37, II, da $\mathrm{CF} / 1988)$.

III - Não forma vínculo de emprego com o tomador a contratação de serviços de vigilância (Lei ${ }^{\circ} 7.102$, de 20.06.1983) e de conservação e limpeza, bem como a de serviços especializados ligados à atividademeio do tomador, desde que inexistente a pessoalidade e a subordinação direta.

IV - O inadimplemento das obrigações trabalhistas, por parte do empregador, implica a responsabilidade subsidiária do tomador dos serviços quanto àquelas obrigações, desde que haja participado da relação processual e conste também do título executivo judicial.

V - Os entes integrantes da Administração Pública direta e indireta respondem subsidiariamente, nas mesmas condições do item IV, caso evidenciada a sua conduta culposa no cumprimento das obrigações da Lei n. ${ }^{\circ}$ 8.666, de 21.06.1993, especialmente na fiscalização do cumprimento das obrigações contratuais e legais da prestadora de serviço como empregadora. A aludida responsabilidade não decorre 


\section{SEMINÁRIO DE PESQUISA EM CIÊNCIAS HUMANAS - SEPECH \\ Humanidades, Estado e desafios didático-científicos \\ Londrina, 27 a 29 de julho de 2016}

de mero inadimplemento das obrigações trabalhistas assumidas pela empresa regularmente contratada.

VI - A responsabilidade subsidiária do tomador de serviços abrange todas as verbas decorrentes da condenação referentes ao período da prestação laboral.

No item I, vê-se a ilegalidade da contratação por empresa interposta, ou seja, aquela que tão somente intermedia ou "loca" a mão-de-obra junto à tomadora de serviços, que quando configurada forma vínculo diretamente com a tomadora, salvo no caso de trabalho temporário que possui regulamentação específica na Lei no 6.019/1974.

No item II, exclui a possibilidade de formação de vínculo junto à Administração Pública, seja direta ou indireta ainda que ilegal tendo em vista disposição constitucional quanto a necessidade de aprovação em concurso público, salvo cargos em comissão.

Já o item III, trata da possibilidade de contratação de serviços terceirizados de vigilância previsto na lei $\mathrm{n}^{\circ} 7.102 / 1983$, bem como de conservação e limpeza ou de serviços ligados à atividade-meio da empresa, tidos como especializados, desde que manifestamente ausente a pessoalidade e subordinação em face do trabalhador, tendo em vista que a existência dessas duas características, forma vínculo com o tomador de serviços.

Os dispostos nos itens IV, V e VI, tratam da responsabilidade subsidiária do tomador de serviços, quando a terceirizada contratada é inadimplente no tocante às obrigações e débitos trabalhistas, com a ressalva de que o tomador deve ter sido parte passiva na relação processual e seja condenado, constando no título judicial.

No entanto, frente ao capital, a súmula por si só não é capaz de resguardar e proteger os direitos dos trabalhadores.

Muito se defente que a terceirização é uma estratégia adotada pelas empresas a fim de que estas delegam atividades consideradas secundárias, e otimizem a produção, no intuito de focalizar no processo produtivo de sua atividade-fim. Em se tratando de trabalho super especializado, esta é uma modalidade lícita de terceirização.

Quanto a divisão de atividades, entende-se por atividade fim, aquela que se destina ao objetivo final socioeconômico da empresa, usualmente descrito em seu contrato social.

Conceitua ainda a terceirizaçao Maurício Godinho Delgado (2004, p. 438):

Terceirização é o fenômeno pelo qual se dissocia a relação econômica do trabalho da relação jus trabalhista que lhe seria correspondente. É o mecanismo jurídico que permite a um sujeito de direito tomar serviços no mercado de trabalho sem responder, diretamente pela relação empregatícia estabelecida com respectivo trabalhador.

Neste entendimento, deveria este artifício ser exceção à regra ao contrato de trabalho entre empregador e empregado, possibilitada tão somente em ocasiões restritivas, a fim de evitar o descumprimento aos princípios inerentes a relação de trabalho e consagrados constitucionalmente ao empregado.

Contrário sensu, em que pese ser exceção, a mesma é utilizada de forma fraudulenta com escopo de diminuir gastos, flexibilizar a mão de obra, para se eximir de encargos trabalhistas e previdenciários. 


\section{SEMINÁRIO DE PESQUISA EM CIÊNCIAS HUMANAS - SEPECH \\ Humanidades, Estado e desafios didático-científicos \\ Londrina, 27 a 29 de julho de 2016}

Deste modo, caracteriza-se essa delegação uma relação triangular, entre trabalhador, prestador de serviços e o tomador de serviços que continua a ser utilizada como intermediação ou locação de mão de obra, precarizando a relação de trabalho e o trabalhador.

\section{DA ATIVIDADE-MEIO ESSENCIAL À PRODUÇÃO E A CONFIGURAÇÃO DA SUBORDINAÇÃO ESTRUTURAL}

Pela Súmula 331 do TST, é permitida a terceirização da atividade-meio da empresa, quando esta não é sobordinada e impessoal. No entanto, objeto do presente trabalho, é ilustar a importãncia da atividade-meio essencial a cadeia produtiva, onde o terceirizado recebe ordens diretas por ingressar na produção, configurando desta forma a subordinação estrutural deste.

Configurada a subordinação estrutural, esta enseja o necessário para a formação de vínculo do trabalhador junto à tomadora.

Neste sentido, cumpre apresentar brevemente o conceito de subordinação clássica, e do objeto da presente pesquisa, a subordinação estrutural. Assim, a palavra subordinação possui origem latina, subordinatione ou subordinatio, com significado de sujeição, submissão.

No direito do trabalho, a subordinação deriva da relação de sujeição entre duas pessoas derivada do contrato de trabalho firmado, sendo esta denominada subordinação clássica ou jurídica.

Desta forma, a subordinação clássica está prevista no artigo $3^{\circ}$, da Consolidação das Leis do Trabalho: "Considera-se empregado toda pessoa física que prestar serviços de natureza não eventual a empregador, sob a dependência deste e mediante salário".

Em que pese o referido artigo trazer o termo dependência, a doutrina conceitua a dependência do texto legal como subordinação, como é oador entendimento do doutrinador Sergio Pinto Martins (2012, p. 140):

A denominação mais correta é, portanto, subordinação. É também a palavra mais aceita na doutrina e na jurisprudência". Citado autor ainda afirma que a subordinação é"a obrigação que o empregado tem de cumprir as ordens determinadas pelo empregador em decorrência do contrato de trabalho.

Conjunto a ele disciplina Maurício Godinho Delgado (2004, p. 303), sobre a subordinação:

A subordinação classifica-se, inquestionavelmente, como um fenômeno jurídico, derivado do contrato estabelecido entre trabalhador e tomador de serviços, pelo qual o primeiro acolhe o direcionamento objetivo do segundo sobre a forma de efetuação da prestação do trabalho.

De igual modo, Amauri Mascaro Nascimento (2004, p. 407): “o trabalho subordinado é aquele no qual o trabalhador transfere a terceiro o poder de direção sobre 


\section{SEMINÁRIO DE PESQUISA EM CIÊNCIAS HUMANAS - SEPECH \\ Humanidades, Estado e desafios didático-científicos \\ Londrina, 27 a 29 de julho de 2016}

o seu trabalho, sujeitando-se como conseqüência ao poder de organização, ao poder de controle e ao poder disciplinar deste".

Compreendendo o exercício do poder empregatício que instrumentaliza a subordinação jurídica no contexto da relação de emprego, disciplina Nilson de Oliveira Nascimento (2009, p. 46.):

A subordinação consiste na situação jurídica que emana da relação de emprego através da qual o empregado permite que sua força de trabalho seja utilizada como fator de produção na atividade econômica exercida por outrem, comprometendo-se a aceitar o poder de direção do empregador no sentido de dirigir a sua prestação pessoal de serviços.

Assim, a subordinação jurídica partirá de relação jurídica que impõe ônus a ambas as partes, qual seja, para o empregador de valer-se da mão de obra do empregado essencial a sua produção, conjunto a seu poder de direção, e de outro lado, a obrigação do empregado de submeter sua força de trabalho mediante prestação pecuniária.

Discorrido sobre a subordinação clássica, a subordinação estrutural é aquela que é reconhecida como o poder de direção que é exercido sobre o trabalhador terceirização, inserido na cadeia produtiva da empresa, através de atividade-meio que seja essencial à produção.

Inovador nesse entendimento, conceitua Mauricio Godinho Delgado sobre o conceito da subordinação estrutural (2006, p. 45 e 46): "Estrutural é, pois, a subordinação que se manifesta pela inserção do trabalhador na dinâmica do tomador de seus serviços, independentemente de receber (ou não) suas ordens diretas, mas acolhendo, estruturalmente, sua dinâmica de organização e funcionamento".

Desta forma, enquanto que a subordinação clássica é elemento é caracterizada pelo poder direto exercido pelo empregador e requisito para a relação de emprego, a subordinação estrutural é aquela que ocorre quando as atividades realizadas pelo trabalhador terceirizado em atividade-meio que seja essencial à dinâmica operacional da tomadora de serviços, por sua essencialidade, ela exerce o poder diretivo sobre o empregado terceirizado.

A subordinação estrutural trazida por Sergio Pinto Martins (2012, p. 142):

É a que ocorre pelo fato de o trabalhador estar inserido na estrutura da empresa, na sua organização. $O$ trabalhador não é subordinado à estrutura da empresa. Se esta está desestruturada ou não tem estrutura, então não haveria subordinação. A subordinação é decorrente do contrato de hierarquia. O empregado é subordinado em geral a alguma pessoa e não à estrutura da empresa. A estrutura não dá ordens;

Conjuntamente, possui posicionamento o professor Luciano Martinez (2012, p. 131) sobre a subordinação estrutural: "caracterizada pela dispensabilidade de ordem direta (da subordinação direta) do empregador para a formação do vínculo entre os efetivos beneficiários dos serviços e contratados".

Portanto, a subordinação estrutural surge da inserção do trabalhador terceirizado no núcleo da produtividade da empresa, que ao prestar serviços no foco da cadeia produtiva, não possui qualquer autonomia respondendo à comandos por 


\section{SEMINÁRIO DE PESQUISA EM CIÊNCIAS HUMANAS - SEPECH \\ Humanidades, Estado e desafios didático-científicos \\ Londrina, 27 a 29 de julho de 2016}

dirigentes da empresa quando em atividade-meio essencial para a concretização do produto final.

Ao terceirizar atividade-meio essencial à sua produção, o tomador de serviços busca através de empresa prestacional mascarar a subordinação que exerce em face dos terceirizados, o que configura fraude trabalhista, pois, os serviços integram seu rol de atividades essenciais - totalmente inseridas em seu processo produtivo. Logo, as prestadoras de serviços, as terceirizadas atuam como locadoras de mão-de-obra de qualquer tipo de mão de obra.

Afirma ainda Lorena Vasconcelos Porto (2008): que "a subordinação estrutural pode manifestar-se pela simples integração da prestação laborativa do trabalhador nos fins da empresa, independentemente da intensidade das ordens da empresa empregadora".

Desta forma, a aplicação da subordinação estrutural pelo poder judiciário é a forma mais eficaz na precarização do trabalho inovada pelo capital através da terceirização, onde, quando praticado poder diretivo direto pela tomadora de serviços, deve-se reconhecer o vínculo empregatício do tercerizado com esta, e demais direitos trabalhistas.

\section{DA APLICAÇÃO DA SUBORDINAÇÃO ESTRUTUTAL PELO PODER JUDICIÁRIO}

A subordinação estrutural trás um novo conceito em virtude disso, é tratada com cautela pela jurisprudência pátria, para identificar no âmbito da terceirização a importancia da atividade meio essencial e real do trabalhador, que enseja a subordinação entre empregado e empresa tomadora de serviços,

Essa modalidade de subordinação, analisa o empregador, que ordena a produção como todo, onde será a atividade do trabalhador, integrada à produção, e essencial a esta.

Deste modo, a atividade desenvolvida pelo trabalhador é pressuposto para a realização do produto fim almejado pela empresa, que agrega o trabalhador na cadeia produtiva, e sua subtração torna-se impossível, caracterizado o contexto específico da subordinação estrutural.

Assim, vale-se o judiciário do contexto da subordinação estrutural, nos casos em que a maioria das atividades realizadas pelos terceirizados intitulados erroneamente de "atividade-meio", integram a cadeia produtiva, e concretizam o produto final da empresa, este previsto em seu contrato social.

O Tribunal Regional do Trabalho da $9^{a}$ Região, tem aplicado a subordinação em sua espécie estrutural para o reconhecimento de vínculo, conforme:

VÍNCULO DE EMPREGO. SUBORDINAÇÃO ESTRUTURAL. Se, no exercício das funções, o trabalhador executa tarefas inseridas no contexto das atividades essenciais ao processo produtivo da empresa, não se exige, para análise do elemento subordinação, prova de expedição de ordens e fiscalização direta, tampouco a presença do trabalhador no estabelecimento. Basta que se passe a ordenar a produção, o que traduz uma nova forma de organização produtiva, que tem raiz na empresa-mater, e que se ramifica e forma uma nova 


\section{SEMINÁRIO DE PESQUISA EM CIÊNCIAS HUMANAS - SEPECH \\ Humanidades, Estado e desafios didático-científicos \\ Londrina, 27 a 29 de julho de 2016}

espécie de subordinação. Esta, de acordo com a doutrina, denominase "subordinação estrutural", em que o trabalho executado integra a estrutura da empresa, ao inserir o trabalhador na dinâmica empresarial do tomador de serviços, o que atrai a proteção das normas da CLT e, consequentemente, o reconhecimento de vínculo de emprego. Recurso ordinário da autora provido. (RO - TRT-PR00883-2010-749-09-00-2-ACO-21724-2012 - 2A. TURMA, Relator: MARLENE T. FUVERKI SUGUIMATSU. Publicado no DEJT em 18-05-2012)

Ainda, o Tribunal Regional do Trabalho da $2^{\text {a }}$ Região, adota em seus julgados a subordinação estrutural:

Relação de emprego. Subordinação estrutural. Recursos para esvaziamento de direitos do trabalhador. $\mathrm{O}$ fenômeno retratado nestes autos tem ocorrido com frequência no sistema produtivo pósindustrial, qual seja, o da "subordinação estrutural", tendo como conceito - (...) a subordinação que se manifesta pela inserção do trabalhador na dinâmica do tomador de seus serviços, independentemente de receber (ou não) suas ordens diretas, mas acolhendo, estruturalmente, sua dinâmica de organização e funcionamento". E o comportamento do tomador de serviços de não firmar contrato de trabalho nessa hipótese tem por objetivo desvirtuar, impedir ou fraudar as normas trabalhistas, sendo nulo outro tipo de pactuação, nos termos do artigo $9^{\circ}$, da CLT, importando no reconhecimento do vínculo de emprego.[...]. (RO-TRT-SP0215800-39.2009.5.02.0018 - $4^{\text {a }}$ TURMA, Relatora: Ivani Contini Bramante. Publicado no DEJT em 06-07-2012)

[...] As transformações no cenário econônico e social dos últimos anos, manifestada por várias circunstâncias, entre as quais a descentralização produtiva, a inovação tecnológica e o aparecimento de novas profissões advindas da transição de uma economia industrial para uma economia pós industrial ou de serviços, contribuíram para colocar em crise a tradicional dicotomia entre trabalho autonomo e trabalho subordinado. Daí ter surgido a hipótese chamada de trabalho parassubordinado ou coordenado ou ainda como prefere a OIT: "relações de trabalho de ambiguidade objetiva". Tratase de uma zona cinzenta entre a relação de trabalho e a relação de emprego. E para se tornar translúcida essa zona cinzenta há de analisar a presença, em cada caso, dos requisitos legais constantes nos artigos $2^{\circ}$ e $3^{\circ}$ da CLT. Cabe verificar se configurada a situação em que o trabalhador, supostamente autonomo, mas habitualmente inserido na atividade produtiva alheia, a despeito de ter controle sobre a atividade economica. É o que a doutrina moderna chama de subordinação estrutural. Hipótese em que a prestação do trabalho ingressa na empresa através de um contrato de prestação de trabalho, mas adere às atividades da empresa. A suposta impessoalidade da disposição do trabalho não afasta a circunstancia de ter sido contratado para desenvolver atividade, e não resultado $1^{\text {a }}$ Turma do TRT da 2a Região - Tribunal Regional do Trabalho (2 $2^{\mathrm{a}}$ Região) RO 


\section{SEMINÁRIO DE PESQUISA EM CIÊNCIAS HUMANAS - SEPECH \\ Humanidades, Estado e desafios didático-científicos \\ Londrina, 27 a 29 de julho de 2016}

\section{$00157.2009 .025 .02 .00-7$}

Diante do apresentado, o reconhecimento da subordinação estrutural pela jurisprudência é de suma importância, pois repercute de forma direta quanto a responsabilidade das empresas tomadoras de serviço e consequente formação de vínculo no âmbito da terceirização.

Com a aplicação e reconhecimento da subordinação estrutural a empresa tomadora, antes responsável subsidiária, passa a ser a devedora principal, obrigando-se a proporcionar aos empregados terceirizados os mesmos direitos trabalhistas conferidos a seus empregados diretos, no entanto, não é necessária a caracterização de terceirização ilícita para a admissão da subordinação estrutural.

\section{PROJETO DE LEI No 4330/2004}

O projeto de Lei 4330 de 2004, realizado pelo Sr. Sandro Mabel (PMDB-GO), tem por escopo a discussão no tocante a prestação de serviços da terceirização e seus efeitos. O projeto busca a regulamentação da terceirização no país por lei específica, de modo a expandir as situações hoje regulamentadas pela súmula 331 do Tribunal Superior do Trabalho, transformando a exceção nas relações trabalhista em regra positivada.

Neste sentido, o Artigo $1^{\circ}$ do citado projeto de lei, reafirma o objetivo de regulamentar o contrato de prestação de serviço e seus efeitos, quando o prestador de serviços for sociedade empresária que terceirize empregados ou subcontrate outra empresa para execução de serviço. Logo, verifica-se a legalização da intermediação de mão-de-obra pelas empresas tomadoras de serviços.

No parágrafo único do artigo $1^{\circ}$, faz menção a aplicação subsidiária do Código Civil em seus artigos 421 a 480 e 593 a 609. Em tais artigos encontra-se a disciplina quanto aos contratos em gerais, de modo que tal legislação é utilizada em face de particulares que via de regra ocupam o mesmo patamar, ou seja, não há hipossuficiencia de um em relação ao outro, de modo contrário ao encontrado na legislação trabalhista que pelo princípio protetor já reconhece tal diferença entre as partes.

No artigo $2^{\circ}$, em seu $\S 1^{\circ}$, ilustra a responsabilidade da prestadora de serviços de contratar e remunerar seu empregados, ou ainda, subcontratar outra empresa para tal ato, que configura a quarteirização, também combatida pela justiça trabalhista. E no $\S 2^{\circ}$ há cristalina menção que não há configuração de vínculo empregatício entre a empresa tomadora de serviços e os trabalhadores.

Muito sucitamente, pode-se ter ideia de que a norma que, atualmente foi aprovada na Câmara dos deputados, e encontra-se tramitando no Senado. Se aprovada, incorrerá em graves prejuízos sociais e em sérias violações à Constituição Federal, em nítida afronta ao Estado democrático de direito, pois, o trabalhador será como mercadoria, objeto de negociação entre empresas, é a cristalina comercialização da força de trabalho. 


\section{SEMINÁRIO DE PESQUISA EM CIÊNCIAS HUMANAS - SEPECH \\ Humanidades, Estado e desafios didático-científicos \\ Londrina, 27 a 29 de julho de 2016}

\section{CONSIDERAÇÕES FINAIS}

Pode-se verificar na presente pesquisa o crescimento da atividade terceirizada nos últimos anos, em decorrência da busca da geração de lucros contínua do capital após cenários de crises. Uma dessas formas, é a flexibilização do contrato de trabalho, que precariza a relação de emprego, e ceifa direitos dos trabalhadores consagrados pela Constição Federal de 1988.

Através do apresentado, verificou-se a realidade da problemática quanto a utilização da terceirização, seus limites e permissivos analisados pelo poder judiciário, em conjunto a ausência de legislação específica, uma vez que o projeto de lei que aborda o assunto, não favorece, nem protege de fato o trabalhador, parte hipossuficiente na relação triangular com a prestadora de serviços, e tomadora destes.

Como forma de preservar o trabalhador terceirizado, abordou-se o conceito bem como a necessidade da aplicação da subordinação estrutural em se tratando de atividade-meio essencial à produção.

Deste modo, a subordinação deve ser examinada quando a inserção do empregado terceirizado na dinâmica da empresa tomadora de serviços, e em razão disso, caso sua atividade seja essencial para o produto final, deve ser aplicada a subordinação estrutural, com o consequente reconhecimetno de vínculo junto à tomadora a fim de garantir os direitos trabalhistas pertinentes ao empregado.

Pode-se concluir que existe forte tendência, e que esta é necessária para aplicação dos Tribunais do Trabalho, da subordinação estrutural para o devido reconhecimento do vínculo empregatício em procedimentos que envolvem a prestação de serviços terceirizados, e intermediação de mão-de-obra realizada pelas empresas tomadoras de serviços.

Posteriormente, pode-se verificar de modo sucinto a intenção do legislador no atual cenário político e econômico, ilustrado pelo projeto de lei $\mathrm{N}^{\circ} 4.330 / 2004$ com aprovação pela Câmara dos Deputados em 2015, e atualmente em apreciação no Senado Federal, onde esta norma permite a banalização da terceirização atualmente como exceção, em confronto aos direitos trabalhistas protegidos pela legislação e súmulas do Superior Tribunal do Trabalho, permitindo sucessivamente e em cadeira a intermediação de mão-de-obra, hoje, combatida.

Inegável que buscou-se no presente a demonstração da precarização das condições de trabalho praticada através da terceirização para a manutenção dos princípios fundamentais da República Federativa do Brasil, (art. $1^{\circ}$, inciso II, da Constituição Federal), da dignidade da pessoa humana (art. $1^{\circ}$, inciso III, da Constituição Federal) e os valores sociais do trabalho (art. $1^{\circ}$, inciso IV, da Constituição Federal).

\section{REFERÊNCIAS}

BARROS, Alice Monteiro de. Curso de direito do trabalho. 7. ed., rev. e ampl. São Paulo: LTr, 2011

BRASIL. Consolidação das Leis do Trabalho. Armando Casimiro Costa, Irany Ferrari, Melchíades Rodrigues Martins. 39 ed. São Paulo: LTr, 2012. 


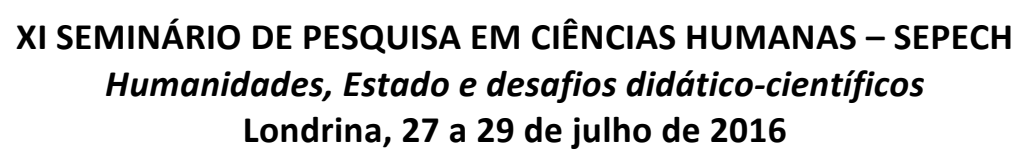

BRASIL. Constituição (1988). Constituição da República Federativa do Brasil: promulgada em 5 de outubro de 1988. 46. ed., atual. e ampl. São Paulo: Saraiva, 2012.

CASSAR, Vólia Bonfim. Direito do Trabalho $8^{\text {a }}$ Ed. rev. e atual-Ed. Editora Metodo, RJ 2013.

CARELLI, Rodrigo de Lacerda. Terceirização e intermediação de mão-de-obra: ruptura do sistema trabalhista, precarização do trabalho e exclusão social. Rio de Janeiro: Renovar, 2003.

DELGADO, Mauricio Godinho. Curso de direito do trabalho $3^{\text {a }}$ Ed. Editora LTR - SP 2004

DELGADO, Mauricio Godinho. Direitos Fundamentais na Relação de Trabalho, Revista do Ministério Público do Trabalho no 31, março de 2006.

MARTINEZ, Luciano. Curso de Direito do Trabalho. 3ed. São Paulo: Saraiva, 2012.

MARTINS, Sergio Pinto. A terceirização e o direito do trabalho. 9. ed. São Paulo: Atlas, 2009.

MARTINS, Sergio Pinto. Direito do trabalho. 28. Ed. São Paulo: Atlas, 2012.

NASCIMENTO, Amauri Mascaro. Curso de direito do trabalho: história e teoria geral do direito do trabalho : relações individuais e coletivas do trabalho. 26. ed., rev., atual. e ampl. São Paulo: Saraiva, 2011.

NASCIMENTO Nilson de Oliveira. Manual do Poder Diretivo. São Paulo: LTr, 2009.

PORTO, Lorena Vasconcelos. A subordinação no contrato de emprego: desconstrução, reconstrução e universalização do conceito jurídico. Belo Horizonte: 2008. Disponível

em: $<$ http://www.biblioteca.pucminas.br/teses/Direito_PortoLV_1.pdf.> Acesso em: 29 de Dezembro de 2015.

RO - TRT-PR-00883-2010-749-09-00-2-ACO-21724-2012 - 2A. TURMA, Relator: MARLENE T. FUVERKI SUGUIMATSU. Publicado no DEJT em 18-05-2012

RO-TRT-SP- 0215800-39.2009.5.02.0018 - $4^{\mathrm{a}}$ TURMA, Relatora: Ivani Contini Bramante. Publicado no DEJT em 06-07-2012) 